José Armando Montoya Macías 


\section{Virtudes públicas como propuesta de una ética civil actual}

\section{Introducción}

En la ética han sido postuladas un conjunto de teorías con las que se ha buscado reflexionar en relación a los aspectos implicados en la moralidad humana expresada en comportamientos y acciones de las personas. También han sido propuestas con el objetivo de ofrecer respuestas a una pregunta importante ¿En qué consiste una acción correcta y desde qué criterios podría considerarse como tal? Estas teorías se ubican en lo conceptualizado como éticas normativas.

En el último capítulo nos ocuparemos en desarrollar nuestra propuesta de una ética civil basada en virtudes públicas. Comenzaremos explicando por qué es necesario que en la actualidad sea postulado un catálogo de virtudes públicas. También hablaremos, un poco, de lo que consiste he implica una ética cívica. Posteriormente abordaremos las virtudes públicas que Victoria Camps considera como necesarias y por ende debieran formar parte del carácter del actual ciudadano democrático. Luego aportaremos una pequeña descripción de cada una, puesto que la autora no abordó de manera suficiente cada virtud. Terminaremos reflexionando sobre si sería viable proponer una ética civil basada en virtudes públicas. Lo haremos refiriendo los aspectos que a nuestro juicio debe contemplar la propuesta citada para lograr que pueda ser planteada y difundida con resultados satisfactorios.

\section{¿Por qué proponer una ética civil basada en virtudes públicas?}

En este trabajo plantearemos una ética civil basada en virtudes públicas. Lo haremos tomando como punto de partida las reflexiones aportadas por la filósofa española 
Victoria Camps en torno al tema, específicamente en su texto titulado Virtudes públicas. Allí hace referencia a un diagnóstico que exhibe los principales fallos y vicios presentes en la democracia como forma de vida social actual. Por consiguiente, la autora cree que es necesario que los ciudadanos pertenecientes a un contexto democrático adquieran y pongan en práctica un conjunto de cualidades, actitudes y disposiciones que contribuyan al logro de una mejor vida colectiva, así como a la solución de muchos problemas actualmente apremiantes que a todos nos deberían preocupar.

Sin embargo, notamos que Camps propuso una ética civil basada en virtudes de una manera demasiado general, por lo cual vemos oportuno reflexionar sobre sus conclusiones resaltando aspectos que creemos ella no tomó muy en cuenta. También buscamos aportar algunas reflexiones adicionales que, pensamos, podrán contribuir a que la propuesta de Camps sea mejor fundamentada, se presente como más verosímil y en último término pueda considerarse interesante para que nos motive a llevar a cabo acciones que determinen mejoras en nuestra actual sociedad liberal y democrática.

Comenzaremos nuestras reflexiones explicando por qué es necesario en la actualidad proponer una ética ciudadana basada en virtudes públicas. Dentro de la explicación señalaremos en qué consiste una ética cívica y posteriormente a esta incorporar una definición de virtud que fundamente el catálogo de virtudes públicas, el cual abordaremos más adelante.

La razón principal por la que valoramos, como necesario, que actualmente sea propuesto un catálogo de virtudes públicas se debe al surgimiento de lo que es conceptualizado como individualismo. Este consiste en el postulado de que todas las personas tienen el derecho fundamental de ser libres, en lo que respecta a tomar decisiones, sobre cómo dirigir su vida, siempre y cuando no afecten a terceros. Si bien el individualismo puede valorarse como la materialización de un importante progreso moral, no por ello ha sido exento de implicar consecuencias negativas. Una de ellas es que en la actualidad la mayoría de las personas manifiesten desinterés y falta de

${ }^{1}$ Cfr. Camps, V. (1990). Virtudes públicas. Espasa-Calpe. España. 
preocupación por la presencia evidente de problemáticas sociales que a todos nos conciernen por la simple razón de pertenecer a una sociedad. Así, nuestro diagnóstico sobre el presente hace ver que la tendencia social actual consiste en velar por los intereses personales y los de la propia familia dejando de lado cualquier posible colaboración, por muy mínima que pueda ser, en función de la solución de conflictos sociales apremiantes.

Esta tendencia también es incentivada por el capitalismo, que seduce a las personas de manera que deseen consumir diversos bienes y servicios, acción que es valorada como un importante objetivo de vida. Por este motivo distrae a los individuos impidiéndoles ser conscientes sobre todo lo que acontece en su entorno, lo que en último término implica que los actuales ciudadanos no se preocupen por la presencia de problemas sociales importantes. No se afirma que es incorrecto consumir en pro de satisfacer necesidades y mejorar la vida de las personas, lo preocupante radica en que la mayoría de los individuos centran su vida en esto y no tomen en cuenta otros aspectos importantes. Uno de ellos sería la participación democrática fructífera que contribuya a la presencia de mejoras sociales que a fin de cuentas cualquier persona razonable anhela su manifestación.

El último aspecto implicado en el presente diagnóstico es el que reprochó Alasdair MacIntyre a la modernidad, a saber, la pérdida de cualquier noción teleológica sobre el bien, anteriormente compartida por un colectivo social que fundamentaba un catálogo de virtudes específico, el cual, en última instancia, guiaba éticamente a los sujetos. Camps hace mención de las ideas sobre el bien que eran compartidas socialmente y por ello orientaban a los miembros de cualquier tradición moral. Para Aristóteles y la antigua Grecia el bien apuntaba hacia la formación de un buen ciudadano. En la época medieval estaba vinculado con la idea de una autoridad trascendente y divina (Dios) a quien se le debía obediencia. Estas ideas en torno al bien indicaban cuales eran las virtudes necesarias que debían formar parte de un catálogo que se valoraba como 
deseable el hecho de que las personas las adoptaran y pusieran en práctica. ${ }^{2}$

En cambio, a partir de la modernidad lo único que se propusieron fueron normas morales que eran impuestas a las personas sin algún soporte teleológico, que justificara por qué era considerado importante que los agentes siguieran ciertas reglas y comportamientos. Esto determinó el surgimiento de lo conocido como ética deóntica. Su máximo exponente fue el filósofo alemán Immanuel Kant.

Una de las razones ofrecidas sobre por qué estamos partiendo de las ideas teóricas propias de la ética de la virtud, plantea que esta teoría nos permite identificar necesidades específicas de un contexto. Estas nos ayudan a proponer una noción teleológica, sobre el bien, de la que se desprenderá un catálogo de actitudes y disposiciones subjetivas relevantes. Partiendo del diagnóstico antes planteado, es evidente que en la actualidad necesitamos proponer una idea sobre el bien que fundamente un catálogo de virtudes funcional en el presente. Quien ha reflexionado sobre esto es Victoria Camps, en su texto antes citado. Por esta razón nos guiaremos con los postulados que ella nos ofrece en referencia a una aplicación contemporánea de la ética de las virtudes, a saber, lo que ella define como virtudes públicas.

La noción actual sobre el bien, misma que en teoría debería ser compartida socialmente, Camps la hace ver en el siguiente fragmento:

Aunque nuestras creencias sean dispares he inconmensurables, por muy plural que sea la sociedad contemporánea, si algo significa la moral, es el compartir un mismo punto de vista respecto a la necesidad de defender unos derechos fundamentales de todos y cada uno de los seres humanos. Pues bien, la asunción de tales derechos si es auténtica, ha de generar unas actitudes, unas disposiciones, que son las virtudes públicas. ${ }^{3}$

Digamos que la cita anterior resume la propuesta ofrecida por la autora en referencia a una aplicación contemporánea de la ética de la virtud. En primer lugar, hace énfasis en el hecho de que actualmente estamos inmersos en una sociedad pluralista, 
donde existen demasiados sistemas de creencias que orientan la vida, así como las acciones de distintos grupos de personas. Esto fue ocasionado, precisamente, gracias a los derechos humanos implicados en la noción de individualismo. Sin embargo, idealmente todas las personas tendríamos que estar de acuerdo sobre una defensa y búsqueda común, a saber, el mejor cumplimiento posible de los derechos humanos fundamentales, lo cual, en teoría, es algo que toda persona razonable y verdaderamente moral desearía. Por último, si los individuos, en verdad, comparten la búsqueda señalada, entonces serán impulsados a adquirir una serie de actitudes, cualidades y disposiciones morales, las virtudes públicas.

Por lo tanto, la idea del bien que en nuestro contexto democrático actual determinaría unanimidad social, es la referente a la búsqueda de la aplicación eficaz de los derechos humanos. La misma nos remite a lo que se denomina ética cívica, o según la propuesta de Adela Cortina, será una ética de mínimos. Antes de continuar con la mención de unas aclaraciones previas al catálogo de virtudes públicas que abordaremos, explicaremos un poco lo que consiste una ética de mínimos.

Según Adela Cortina, una ética cívica, o de mínimos, surge como algo necesario, ya que su principal función es asumir un fenómeno social innegable: el pluralismo. Esto es importante dado que se propone la posibilidad de una convivencia armónica entre personas con distintas creencias religiosas, agnósticas, filosóficas, políticas, entre otras. Así pues, esta ética de mínimos comunes demanda que los individuos compartan un conjunto de valores, normas e ideales que determinen hacer valoraciones morales de los diferentes sectores de la sociedad, así como la realización de proyectos sociales consensuados. En pocas palabras, una ética de mínimos se trata de que las personas con distintas maneras de pensar sobre diversas cuestiones, estén de acuerdo con que es posible y enriquecedor convivir entre sí, a pesar de sus diferencias. Además, también se trata de que estén convencidas de que hacerlo es algo bueno porque cada sujeto tiene la libertad de tomar decisiones sobre qué proyectos le permitirán ser feliz, siempre y 
cuando no se impida a otros esto. ${ }^{4}$

La principal característica que distingue a una ética de mínimos es que constituye una moral pública, es decir, aplicada a la vida social de los ciudadanos. Se ocupa en buscar todo lo que podría considerarse como justo sin importar sentimientos o valoraciones subjetivas respecto a ello. Por otra parte, Cortina ubica a la ética de máximos que está relacionada con creencias personales, las cuales determinan lo que distintos individuos y sistemas de creencias consideran como bueno, a saber, aquello que desde una u otra perspectiva encaminaría a una vida feliz. Entonces, la ética de mínimos pretende ser más racional y por ende objetiva, mientras que la de máximos se distingue debido a su flexibilidad; esta en el sentido de tomar en cuenta las creencias e ideales propios de cada sujeto o grupo de personas. ${ }^{5}$

Ya explicado, de manera general, en lo que consiste una ética cívica, cabe preguntarnos ¿De qué manera podrían materializarse los requerimientos inherentes a esta clase de ética? Podemos entender que Cortina habla en torno a asumir un conjunto de valores mínimos que todos los miembros de una sociedad pusieran en práctica. Sin embargo, debemos decir que la autora no menciona una descripción del contenido específico de cada uno de estos valores y creencias. Por esta razón pensamos que llegados a este punto conviene retomar la propuesta de Victoria Camps sobre un catálogo de virtudes públicas, lo que realizaremos más adelante.

Antes de proceder al desarrollo del catálogo como tal, consideramos fundamental previamente aclarar unas cosas. La primera es justificar por qué razón estamos hablando de virtudes en lugar de simplemente valores éticos. La razón de esto puede identificarse recordando la definición general de virtud que tomamos de James Rachels. Las virtudes constituyen rasgos de carácter manifestados en acciones y actitudes habituales. De esta definición se deriva la consecuencia de que la propuesta de una ética civil basada en virtudes públicas puede valorarse como más prometedora. Esto en el sentido de que las

\footnotetext{
${ }^{4}$ Cfr. Cortina, Adela. Ética de la empresa, Madrid, Trota, 2008, pp. 37-38.

${ }^{5}$ Cfr. Cortina, Adela Ética civil y religión, Madrid, PPC 3a ed., 2002, pp. 63-64.
} 
personas en tanto miembros de una sociedad no sólo se limitarían a observar normas de conducta por causa de imposición, sino que se les invitaría a practicar ciertas actitudes y disposiciones morales que con el tiempo se volverán hábitos de comportamiento. Y si con Aristóteles el propósito de adquirir virtudes consiste en la forja del carácter personal, entonces las virtudes públicas que citaremos buscan la forja de un buen carácter ciudadano que permita lograr mejoras sociales considerables.

Así pues, citar virtudes en lugar de solamente valores nos remite a la posibilidad de hablar sobre la educación de las personas, misma que se propusiera como objetivo fundamental que los ciudadanos adquieran las cualidades y actitudes que le son demandadas por estar inmersos en un contexto democrático. En pocas palabras, las virtudes, debido a las características que poseen, digamos que serían manifestadas de manera más constante ya que son el resultado de la forja del carácter. En cambio, cuando se habla de valores vemos que ello posee menor peso motivacional, pues se suelen considerar como constituyentes de normas y reglas que simplemente son impuestas a las personas.

También las virtudes siempre contienen un trasfondo teleológico claro que les otorga un sentido y a su vez justifica la importancia en cuanto a su manifestación en el carácter personal. Por otro lado, si bien la propuesta de valores es motivada por causa de la presencia de necesidades y objetivos propios de un contexto, su explicación y justificación no suele ser demasiado persuasiva como para que logre convencer a los individuos acerca de su importancia real.

Sin embargo, lo dicho anteriormente no debe entenderse de manera que estamos descartando hablar de valores éticos. En todo caso, cabe aclarar que estos remiten a los ideales morales trasfondo que proveen de contenido a cualquier catálogo de virtudes. Pero limitarse a postular solamente valores es algo que no despierta mucho interés y entusiasmo en las personas. Entonces sugerimos hablar de valores comprendiéndolos como aquellos ideales morales trasfondo que otorgan importancia moral a cualquier catálogo de virtudes, por lo que forman parte de la teoría. Proponemos ver a las virtudes 
como las actitudes y disposiciones morales que constituirían un buen carácter ciudadano que colabore con la realización de los valores considerados como necesarios. Entonces, las virtudes forman parte de la práctica.

Otra cuestión que debemos aclarar es el sentido teleológico inherente al catálogo de virtudes públicas que plantearemos, el cual a su vez dará contenido a la definición de virtud que será el punto de partida del mismo. El trasfondo teleológico propio de las virtudes públicas ya lo mencionamos antes cuando hicimos referencia a la noción sobre el bien, implicará que en la actualidad es deseable que los miembros de una sociedad democrática la compartan, esto a pesar de sus diferencias en cuanto a creencias y otros aspectos. Sin embargo, es necesario señalar este trasfondo teleológico con mayor precisión. Quien lo hace es Victoria Camps, cuando nos dice: "Si los derechos fundamentales son la igualdad y la libertad, sea cual sea la realización de cada uno de ambos valores, ha de ser posible hablar de unas prácticas, de unas actitudes, de unas disposiciones coherentes con la búsqueda de la igualdad y la libertad para todos. A esas disposiciones es a lo que llamo "virtudes públicas"”. ${ }^{6}$

Lo dicho por la autora nos permite comprender anticipadamente la naturaleza del catálogo de virtudes citado. Afirmamos esto porque la búsqueda del cumplimiento de los dos derechos humanos, mencionados en el fragmento tiene como propósito lograr mayor bienestar social. Este bienestar será posible siempre y cuando cada ciudadano contribuya expresando en su carácter un conjunto de cualidades y disposiciones morales. Así, a cada uno de los derechos: como la libertad y la igualdad, corresponde sus respectivas virtudes relevantes que encaminarán a su cumplimiento efectivo. Por lo tanto, el fin que justifica el hecho de que a los ciudadanos se les invite a adquirir y llevar a la práctica las virtudes públicas consiste justamente en lograr mayor bienestar social que beneficie a todos. Y no puede negarse que cualquier persona razonable a fin de cuentas desea este bienestar.

Creemos que lo antes dicho constituye una explicación que justifica el hecho en cuanto a esperar de los ciudadanos la manifestación práctica y habitual de ciertas

${ }^{6}$ Camps, V., Op. Cit., p. 22. 
actitudes y disposiciones morales. Si bien es cierto que la explicación es breve y simple, no por ello deja de ser intuitiva para quienes estén dispuestos a asumir el compromiso de participar en pro de lograr el cumplimiento de los derechos humanos.

Entonces, el concepto de virtud que fungirá como el soporte del catálogo de virtudes públicas sería definido de la siguiente manera: la virtud es una cualidad de un ciudadano democrático que contribuye al cumplimiento con una serie de valores cívicos necesarios para ver reflejada la manifestación práctica de los derechos humanos fundamentales. Ahora bien, no podemos olvidar que cualquier concepto de virtud postulado durante la historia de la ética ha surgido a partir de un contexto y tradición social, tal como lo indica MacIntyre. Puesto que las virtudes públicas que analizaremos se enmarcan en el contexto de la actual sociedad democrática, entonces vemos necesario tener clara la definición de democracia que más se puede relacionar con estas.

Han sido propuestas demasiadas definiciones en torno al concepto de democracia. La más conocida es aquella aportada por el filósofo y jurista Norberto Bobbio, la cual denomina como una definición mínima de democracia. El autor define el concepto afirmando que consiste en un conjunto de procedimientos para elegir a las personas que se encargarán de la toma de decisiones importantes para un colectivo. También se trata de reglas a seguir con el objetivo de que sean tomadas esas decisiones cruciales. Las dos principales son la de la mayoría y también la de unanimidad. ${ }^{7}$ A esta definición se le conoce como democracia procedimental, debido a lo señalado anteriormente. Sin embargo, la democracia no se limita a la toma de decisiones que afectarán a cualquier colectivo de personas, sino que también implica que los individuos de una sociedad posean una serie de libertades y derechos fundamentales que posibilitarán su participación democrática efectiva. ${ }^{8}$

Partiendo de lo anterior, proponemos definir a la democracia en los siguientes términos: 'La democracia es el contexto social en el que todas las personas sin importar

\footnotetext{
${ }^{7}$ Cfr. Bobbio, Norberto El futuro de la democracia, (Trad. José F. Fernández Santillán), México, Fondo de cultura económica, 1986, pp. 14-15.

${ }^{8}$ Cfr. Ibid., pp. 14-16.
} 
sus diferencias, pueden convivir en libertad y armonía. También constituye la posibilidad de una búsqueda común de mayor bienestar social mediante el cumplimiento real de los derechos humanos fundamentales'. Proponemos asumir esta definición en torno a la democracia para que no nos limitemos a considerarla solamente como algo que contribuye a la toma de decisiones colectivas, sino que también se trata de que todos los miembros de una sociedad, que se presuma democrática, trabajen en común en pro de conseguir mejoras sociales significativas, lo cual puede englobarse en la búsqueda de la justicia. Entonces, sugerimos tener presente la definición que aportamos cuando estemos abordando cada una de las virtudes públicas.

Por último, cabe aclarar por qué Camps, y nosotros, plantearemos unas virtudes públicas. A este respecto, la autora plantea que la moral es pública en tanto aquello que haga una persona afecte a otros individuos y a la sociedad en general. La moral se ocupa en la búsqueda de la justicia, la cual requiere que los ciudadanos asuman una serie de ideales y comportamientos compatibles con esta búsqueda. Esta idea nos remite a la distinción de Cortina que referimos más arriba entre una ética de mínimos respecto a la de máximos. La de mínimos es pública y general, mientras que la de máximos es más subjetiva porque es orientada según los ideales y preferencias de cada persona.

Además, según Camps hablar de unas virtudes públicas tiene como propósito hacer frente a la tendencia de solamente refinar la moral privada con prescripciones de virtudes que moderan las acciones de los individuos, dejando de lado los asuntos que competen a la pública. Así, la autora nos recuerda que las virtudes constituyen cualidades y modos de ser dirigidas a los demás, por lo que tienen que formar parte de una ética pública. Por lo tanto, el fin último de unas virtudes públicas consiste en una moral que determine cambios sociales evidentes y significativos. Procederemos a desarrollar el catálogo de virtudes públicas que constituye nuestra propuesta de una aplicación contemporánea de la ética de la virtud. 


\section{Virtudes para una ética ciudadana actual}

Es momento de abordar aquellas que, según Victoria Camps, son las virtudes públicas imprescindibles en el carácter de los ciudadanos inmersos en la actual sociedad liberal y democrática. En primer lugar, citaremos brevemente las reflexiones que planteó la autora respecto a cada virtud. Después nosotros complementaremos sus afirmaciones. Es importante aclarar que Camps no expone una descripción completa de cada virtud pública como tal, más bien habla acerca de lo que implicaría su manifestación práctica. Por ende, nosotros contribuiremos aportando una pequeña descripción relevante correspondiente a cada cualidad.

La primera virtud que la filósofa española plantea es la solidaridad. Ella la comprende como una cualidad del ciudadano, su propósito radica en fungir como complemento de la justicia. Según Camps, la justicia es la virtud por excelencia de la cual se derivan todas las virtudes éticas. Sin embargo, cuenta con sus respectivas insuficiencias prácticas. En muchos casos no se ve la presencia de la justicia, concretamente en los referentes a las desigualdades sociales, nacionales, raciales, entre otras. Además, se nota la falta de justicia debido principalmente a los asares de la propia vida como son vivir en un país con miseria económica, tener que morir en algún momento, pertenecer a un grupo de personas a las que se discrimina, etc.

Así pues, de acuerdo con Camps, la solidaridad se ocuparía en lo posible de hacer frente a casos y situaciones en los que la justicia es insuficiente. Por lo tanto, Con esta virtud se pretende que los ciudadanos muestren empatía ante las dificultades y situaciones difíciles de muchas personas y, en última instancia, contribuyan ayudándoles en lo que sea posible, tal como lo señala la autora a continuación: "La solidaridad es una práctica que está más acá, pero también va más allá de la justicia: la fidelidad al amigo, la comprensión del maltratado, el apoyo al perseguido, la apuesta por causas impopulares o perdidas, todo eso puede no constituir un deber propiamente de justicia, pero si es un

${ }^{9}$ Cfr. Camps, V., op. cit., pp. 31-33. 
deber de solidaridad". ${ }^{10}$

Camps finaliza sus reflexiones en torno a la solidaridad afirmando que debe ser una virtud selectiva, es decir, ser aplicada, específicamente, a las personas desfavorecidas y socialmente segregadas. También plantea que debe ser una cualidad que pase de lo más privado a lo más público. Esto implica que los ciudadanos no solamente manifiesten solidaridad con quienes pertenecen a su familia y amigos, sino también con cualquier persona. ${ }^{\text {II }}$

Todo lo antes expuesto hace notar que falta una descripción más específica con respecto a la virtud de solidaridad. Estamos de acuerdo con Camps que se trata de una cualidad ciudadana que tiene como fin ayudar a las personas que lo necesitan. Sin embargo, cabe preguntarnos ¿De qué manera tendría que ser manifestada dicha virtud? Es complicado proponer algo a este respecto, pero intentaremos hacerlo. Puesto que las virtudes son cualidades y actitudes que requieren práctica constante para que sean manifestadas en el carácter personal, los ciudadanos tendrían que comenzar adoptando una serie de actitudes que posibilitarían una disposición a la solidaridad. Por ejemplo, una sería la actitud de empatía, la cual posibilita que alguien se interese y preocupe por los demás. Así, un sujeto no podría ser solidario si antes no se caracteriza por ser empático.

Otra actitud de la que depende si alguien será o no solidario es el servicio. Esto significa que apoyar a otros implica llevar a cabo acciones que requieren de esfuerzo personal en pro de aportar algo a los demás. Por lo tanto, si un sujeto está dispuesto a servir a otros, entonces le será más fácil poner en práctica la solidaridad.

Por último, es fundamental que los ciudadanos se caractericen por ser generosos. Esto quiere decir que una persona tenga la disposición de brindar a otros, parte de su tiempo, esfuerzo, recursos económicos y de otra índole, etc. Así, una persona contará con la virtud de solidaridad siempre y cuando tenga por importante la generosidad.

\footnotetext{
${ }^{10}$ Ibid., p. 34.

${ }^{11}$ Cfr. Ibid., pp. 47-48.
} 
Entonces, digamos que la virtud de solidaridad tendría que ser una cualidad manifestada, primero, en pequeñas actitudes con miras a lograr que impacte significativamente a la sociedad. Pero nosotros afirmamos que lo demandado al ciudadano no es que sea solidario a tal punto en que esto constituya un factor de grandes cambios sociales, lo deseable es que todas las personas practiquen esta virtud, por lo menos en pequeñas cosas que beneficiarían a los más necesitados. La solidaridad con grandes impactos concierne más a instituciones corporativas privadas, gubernamentales, asociaciones civiles, etc. Pero es obvio que no todas las personas llegan a este nivel de solidaridad ni tampoco tendría que ser algo obligatorio.

Finalizaremos diciendo que un ciudadano solidario es aquel que está dispuesto a dejar un poco su individualidad y comience a interesarse por los demás prestando servicios y ofreciendo a quien requiere algo de sus recursos. Si todas, o por lo menos la mayoría de las personas tuvieran esta disposición, obviamente podríamos presenciar una sociedad contemporánea más solidaria. Además, también es evidente que esto haría posible el surgimiento de importantes proyectos sociales que impliquen grandes cambios, mismos que mejorarían la vida de mucha gente, tal como ya ha estado ocurriendo en la actualidad. La solidaridad, como virtud pública, no encamina propiamente al cumplimiento con el derecho de igualdad, pero sí daría lugar a mejores condiciones de vida propias de muchos individuos que padecen infortunios.

Otra virtud pública importante de acuerdo con Camps es la responsabilidad, ya que en la actualidad es acuciante definir quién sería el sujeto de la responsabilidad, es decir, quien o quienes tendrían que responder ante males y deficiencias que se presentan en cualquier sociedad y en el mundo como tal. Este constituye el objetivo de la autora al hablar de la responsabilidad como virtud ciudadana. Comienza sus ideas partiendo de la definición básica de responsabilidad. Esta significa tomar una o varias decisiones considerando diferentes alternativas posibles y eligiendo una. Cualquier elección implica consecuencias. Por esta razón, toda persona, institución y dirigentes políticos deben responder ante las consecuencias determinadas por sus deliberaciones. La responsabilidad 
es posible gracias a la libertad.

Después la filósofa española plantea una serie de preguntas ¿La responsabilidad y culpabilidad mantienen una relación necesaria? ¿Puede hablarse de responsabilidad cuando no es posible identificar la relación causal entre un hecho y su agente a quien se culparía? ¿Debemos asumir responsabilidades necesariamente de acontecimientos pasados, o también sobre cuestiones futuras? Estos cuestionamientos constituyen la directriz de las reflexiones que desarrolla Camps. ${ }^{12}$

Ahora bien, la autora plantea un diagnóstico en relación a la situación actual de la responsabilidad. En primer lugar, dice que actualmente es difícil fundamentar una responsabilidad social clara porque no existe una idea totalmente consensuada del bien y de lo bueno. En última instancia esto determina la carencia de una identidad social sólida con la que sus miembros puedan comprometerse y dar cuentas por sus decisiones. En segundo lugar, hace ver que actualmente no es sencillo señalar a un sujeto de la responsabilidad. Lo único que ha ocurrido es que se ha culpado a la política por causa de conflictos sociales y mundiales. Aunado a esto también se ha manifestado la tendencia de exigir a la política ocuparse de problemas y carencias sociales para las que muchas veces su labor no es suficiente. ${ }^{13}$

Camps ofrece una posible respuesta a las interrogantes que al principio mencionamos. Respecto a la primera dice que en estos tiempos se ha dejado de lado la costumbre en cuanto a relacionar necesariamente responsabilidad con culpabilidad. Esto debido a lo aclarado en el siguiente fragmento: "La responsabilidad frente al daño no siempre se encuentra vinculada a la noción de culpa. Tenemos al daño frente al daño más que al daño frente a la culpa. ¿Quién es responsable de un accidente aéreo, de la desaparición de la capa de ozono, de la drogadicción, del hambre, del SIDA? Males que deben ser reparados, independientemente de que puedan serle imputados a alguien". ${ }^{14}$ Entonces, lo dicho anteriormente por la autora puede ser entendido de manera que está

\footnotetext{
${ }^{12}$ Cfr. Ibíd., p. 51.

${ }^{13}$ Cfr. Ibid., pp. 51-55 y 68-69.

${ }^{14}$ Ibid., pp. $67-68$.
} 
sugiriendo dejar de buscar culpables de acontecimientos y males mundiales para que en lugar de ello actuemos con el fin de erradicarlos.

Lo planteado anteriormente nos remite a la respuesta de la segunda pregunta que ofrece la filósofa. Aunque muchas veces no exista la relación de causalidad entre algo que ocurre y el agente supuestamente implicado en ello, aun así, es posible hablar de responsabilidad puesto que existen demasiados males en el mundo por los que alguien ha de responder. ${ }^{15}$ De esto se sigue que debe existir responsabilidad a pesar de que no pueda identificarse a un culpable de algo. Es deseable actuar oportunamente con el propósito de evitar la persistencia de muchos males que aquejan a cualquier sociedad, esto en la medida de lo posible ya que muchos de ellos no dependen del hacer humano como son las catástrofes naturales, entre otra clase de infortunios que forman parte de la vida cuyo ejemplo más claro es la muerte.

Por último, sobre la cuestión de si la responsabilidad se trata de responder ante lo ocurrido solamente en el pasado o también en función de lo futuro, la autora señala que en lugar de hacernos la pregunta de ¿Quién ha hecho algo? Interroguemos ¿Qué puede hacerse para evitarlo? Esto implica definir quién sería el sujeto de la responsabilidad. ${ }^{16}$ Aunque Camps no lo dice explícitamente, es obvio que el sujeto de la responsabilidad somos los propios ciudadanos en conjunto con instituciones gubernamentales, asociaciones civiles, etc. Entonces, entendemos que la autora nos invita a que nosotros como ciudadanos pertenecientes a un contexto democrático colaboremos a la par con las instituciones sociales y políticas importantes con el objetivo de distribuir responsabilidades para que no sólo a unos cuantos se les exijan soluciones correspondientes a muchos problemas y males presentes.

Ya abordadas, de manera general, las ideas que plantea Victoria Camps en torno a la virtud citada, ahora cabe preguntarnos ¿En qué consistiría la responsabilidad como una cualidad del actual ciudadano democrático? Para comenzar debemos asumir lo

\footnotetext{
${ }^{15}$ Cfr. Ibid., p. 68.

${ }^{16}$ Cfr. Ibid., pp. 71-72.
} 
afirmado por la filósofa española en referencia al hecho de que actualmente es difícil fundamentar una noción clara de responsabilidad social porque ya no existen grandes ideales compartidos a diferencia de las sociedades antiguas y medievales. La modernidad y las ideas del liberalismo determinaron la pérdida de un sentido colectivo en las personas, es decir, alguien ya no requiere forjar su identidad en su contexto social, sino en sus decisiones y proyectos individuales. No obstante, esto no quiere decir que deba ser olvidada la responsabilidad, pues constituye un elemento importante de la vida cotidiana, de lo contrario nada funcionaría en nuestras familias, instituciones y sociedades.

Ahora bien, si partimos de lo antes dicho, entonces ¿Cómo tendría que manifestarse en las personas la cualidad de ser responsables? A esto respondemos que siempre en primera instancia la responsabilidad comienza por ser individual, debido a que todos tenemos que responder por las consecuencias de nuestras decisiones. Puesto que todos deberíamos estar conscientes de esto, entonces la responsabilidad tendría que constituir una cualidad del ciudadano que le encamine a la toma de decisiones que impliquen consecuencias benéficas, no sólo para sí mismo, sino también para los demás. Esto en último término sería reflejado en la solución por lo menos parcial de muchos problemas sociales tales como la drogadicción, el sida, la delincuencia, entre otros males que en la mayoría de los casos son producto de la toma de muchas decisiones individuales negativas.

Por lo tanto, creemos que la responsabilidad constituye una virtud que necesariamente comienza por ser individual, pero se vuelve pública en tanto que muchas decisiones tomadas por una persona tienen impacto social. Unos ejemplos cotidianos son aquellas que tomamos con respecto al cuidado o descuido de nuestra salud. Lo último implica la demanda de servicios médicos públicos que cuando es en demasía, las consecuencias principales son la presencia de deficiencias y mucho gasto gubernamental en el sector salud. En resumidas cuentas, si los ciudadanos adquieren y ponen en práctica la responsabilidad, cada uno desde su individualidad está contribuyendo al logro de 
grandes cambios como serían tener una ciudad más limpia, menor presencia de contaminación ambiental, instituciones más eficientes, etc. Pero esto sólo es posible si cada uno de nosotros estamos habituados a tomar buenas decisiones que conlleven consecuencias positivas para nuestra vida y también para la sociedad en general.

Ser un ciudadano responsable no implica que cada persona tiene que estar preocupada por los males que aquejan al mundo, más bien serlo contribuye a que no sigan presentándose demasiados problemas que pueden ser evitados si todos los miembros de una sociedad contribuyen desde su individualidad. La responsabilidad necesariamente requiere que las personas adquieran un sentido colectivo que les permitirá tomar conciencia de los conflictos inherentes a su entorno, y esta toma de conciencia les llevará a asumir el compromiso de en la medida de lo posible tomar decisiones con buenas implicaciones colectivas a corto o largo plazo. Por lo tanto, creemos que uno de los retos fundamentales para la educación contemporánea sería fomentar en los individuos ese sentido colectivo que constituye la condición de posibilidad que dará lugar a la presencia de la responsabilidad como virtud pública.

Concluiremos esta parte hablando un poco de la tolerancia que, según Camps, es una virtud democrática fundamental. Esta implica el respeto a otras personas, así como la idea de que todas las creencias y puntos de vista pueden expresarse porque nadie tiene la verdad absoluta sobre cualquier cuestión. Además, la tolerancia constituye la condición para la democracia, puesto que si no está presente se cae en el totalitarismo. Sin embargo, esta virtud también determina el planteamiento de preguntas importantes ¿Dónde acaba la tolerancia y empieza la permisividad? ¿Es lo mismo la tolerancia que la total libertad de costumbres? Según la autora es fundamental el planteamiento de estas interrogantes porque vivimos en una sociedad donde el pluralismo se ha acrecentado y más aún por causa de encontrarnos en una época de las comunicaciones. ${ }^{17}$

Después la filósofa española procede a la revisión de algunas concepciones propuestas por varios autores sobre la tolerancia en las que son abordadas cuestiones

${ }^{17}$ Cfr. Ibid., p. 73. 
como las principales implicaciones que se presentan al ser tolerante, así como sus peligros y contradicciones. Por ende, Camps retoma las preguntas antes mencionadas. En primer lugar, aclara que la tolerancia real se trata de asumir y soportar que otros sean diferentes a nosotros en aquellos aspectos que nos importan como son creencias y formas de vida, por ende, implica un esfuerzo. Pero ser indiferentes ante las diferencias manifiestas por otros no es lo mismo que ser tolerantes. ${ }^{18}$

De lo anterior se deriva la pregunta crucial ¿Qué debería ser tolerado y hasta qué punto? La autora citada afirma que una posible respuesta sería tolerar todo lo que no conlleve daño a otras personas. Esto es sencillo si dañar se limita sólo a daños físicos. No obstante, es verdad que también se daña a las personas cuando se les demanda soportar diferencias de otros individuos que les son desagradables o simplemente reprobables dado que ponen en cuestión las propias convicciones morales y costumbres habituales. Una posible respuesta clara que ensaya Victoria Camps, con relación al límite de la tolerancia, sugiere que puede ser tolerado todo aquello que no implique daños colectivos. Pero esta respuesta pone en relieve la importancia de precisar en qué consistirían estos daños. ${ }^{19}$ La autora resume su propuesta en torno a lo que en teoría debería constituir la tolerancia en los siguientes términos:

La democracia obliga a convivir a seres de creencias y opiniones no coincidentes. Y la convivencia no sólo ha de ser posible, sino agradable. Por eso es preciso desgravar de coacción social aquellas prácticas verdaderamente irrelevantes para el bienestar colectivo. Y, al mismo tiempo, no permitir otras formas de conducta que por sí solas envilecen el todo social. ${ }^{20}$

Lo planteado en el fragmento anterior es razonable, sin embargo, vemos que constituye algo un poco complicado. Establecer una demarcación entre creencias privadas que deberían ser respetadas respecto de aquellas que afectarían al bien común constituye un desafío filosófico que motiva al desarrollo de muchas reflexiones éticas contemporáneas.

En todo lo postulado por Camps con relación a la tolerancia podemos notar que en lugar de proponer una descripción de esta como virtud pública, se ocupó más en

\footnotetext{
${ }^{18}$ Cfr. Ibid., p. 86.

${ }^{19}$ Cfr. Ibid., pp. 88-89.

${ }^{20}$ Ibid., p. 90.
} 
reflexionar sobre sus consecuencias que dan lugar a interrogantes como las mencionadas más arriba. Ahora bien, si nos proponemos describir a la tolerancia como una virtud fundamental en el carácter ciudadano, sugerimos que debería manifestarse como sigue. Creemos que ser tolerante no se trata solamente de soportar diferencias reflejadas en otras personas las cuales vemos como desagradables. Más bien, proponemos que la tolerancia constituya una cualidad del ciudadano que le permita mostrar apertura ante creencias, opiniones y costumbres distintas a las propias. Esto es deseable porque más que la posibilidad de respetar a otros, también contribuiría en el sentido de que podamos reflexionar acerca de si aquellos aspectos que vemos en otros pueden ayudarnos a mejorar en algo o simplemente tendríamos que descartarlos puesto que no serían benéficos para nuestra vida. Además, una actitud tolerante nos beneficiaría en el sentido de que estaríamos abiertos a la obtención de nuevos conocimientos, así como de nuevas ideas con las que podríamos darnos cuenta de que probablemente estamos equivocados en cuanto a creencias, costumbres, entre otros aspectos.

Sin embargo, la tolerancia no se trata de estar de acuerdo con lo que sea, sino respetar a las personas evitando discriminarlas, excluirlas o simplemente agredirlas por causa de sus diferencias no sólo en cuanto a costumbres y creencias, sino también respecto a rasgos físicos. Así, proponemos extender una actitud tolerante dirigida a la presentación en los individuos de diferencias físicas como son el color de piel y otros rasgos corporales, pues estamos convencidos de que esta clase de tolerancia daría lugar a mejoras sociales considerables. Por lo tanto, a esta extensión de la tolerancia sugerimos denominarla como tolerancia práctica.

Si no estamos equivocados, una tolerancia práctica nos posibilitaría mostrar consideración y solidaridad con quienes son diferentes a nosotros por contar con rasgos físicos distintos, formar parte de un sector social segregado, caracterizarse por ser pobres, etc. En resumen, esta clase de tolerancia nos encaminaría a mostrar las actitudes citadas a todas las personas por la simple razón de que a pesar de sus diferencias son seres humanos con necesidades y sentimientos. Si los seres humanos presumimos ser 
racionales y morales, entonces estamos comprometidos con actuar acorde a una tolerancia práctica.

Concluiremos afirmando que la tolerancia es una virtud pública que permitiría una mejor convivencia entre los miembros de una sociedad porque habría respeto entre ellos. También contribuiría en que las personas adquieran una mente abierta que les permitirá una mayor reflexión y análisis de sus creencias y costumbres, así como las de otros. Finalmente, una tolerancia práctica conllevaría que lleguemos a ser ciudadanos solidarios con quienes sufren de discriminación, segregación y pobreza debido a sus diferencias evidentes.

Por lo tanto, la tolerancia, como virtud pública, contribuiría al cumplimiento de los derechos libertad e igualdad. Colabora en función al logro de la libertad en el sentido de que toda persona no sería juzgada, discriminada y agredida por causa de sus convicciones y costumbres, siempre y cuando no afecte a otros. Entonces, cada sujeto sería libre de elegir sus creencias y el estilo de vida que le aportará felicidad. Por otra parte, la tolerancia permite el cumplimiento con el derecho de igualdad, dado que respetar y valorar a quienes son diferentes a nosotros tendría como consecuencia que muchas personas obtuvieran mayores oportunidades que serían reflejadas en posibilidades de desarrollo en función de adquirir una mejor calidad de vida.

\section{Virtudes públicas ¿Una propuesta viable?}

Una vez abordadas las que a juicio de Victoria Camps son las virtudes públicas imprescindibles dentro de un contexto democrático, es necesario preguntarnos ¿En qué medida puede ser viable esperar que los actuales ciudadanos adquieran y pongan en práctica las virtudes públicas? Antes de responder a la pregunta debemos recordar que en la época democrática actual ya no existen ideas en torno al bien que unifiquen fines sociales con los cuales todos los miembros de una sociedad puedan comprometerse. Esto se debe a que la modernidad y el liberalismo dieron lugar a la gestación del 
individualismo, tal como lo reprochó Alasdair MacIntyre en su texto Tras la virtud. Sin embargo, Victoria Camps partió de la convicción de que actualmente también es posible proponer una noción sobre el bien que unifique propósitos sociales, a saber, el cumplimiento efectivo de los derechos fundamentales libertad e igualdad. A pesar de que compartimos esta opinión, siendo realistas la idea del bien mencionada no posee el mismo peso a diferencia de aquellas difundidas en las tradiciones griega y medieval. La razón de esto es que el individualismo, así como el desarrollo del libre mercado fueron los factores causantes de estragos como el desinterés que muestran los ciudadanos por los acontecimientos y conflictos presentes en su entorno social.

No obstante, lo antes señalado no implica que sea imposible sugerir un catálogo de virtudes públicas que constituya una ética civil actual. Pero es cierto que esto sería prometedor siempre y cuando exista un mayor desarrollo teórico de la propuesta ya que la autora citada en este apartado no trabajó de manera suficiente su teoría en torno a las virtudes públicas. Por esta razón, de manera breve señalaremos los aspectos fundamentales que a nuestro juicio deberían formar parte de la propuesta filosófica en cuestión.

En primer lugar, es necesario concebir un proyecto educativo que se proponga el objetivo de lograr que los ciudadanos adquieran y pongan en práctica las virtudes públicas. Este tendría que ser aplicado en las escuelas tanto de educación básica como media y superior. Pero este proyecto no tendría que limitarse a enseñanzas teóricas, sino que debe aplicarse lo sugerido por Aristóteles en relación a que las virtudes se adquieren mediante la práctica constante de cada una. Para que esto sea posible, consideramos necesario que a los educandos se les involucre en situaciones en las que tengan que ponerse en práctica las virtudes públicas. Esto con el fin de que entiendan la importancia y las implicaciones favorables que determina cada virtud. Así pues, la educación para las virtudes públicas no debe ser meramente teórica, sino práctica puesto que lograr esto último es más sencillo de lo que en primera instancia puede parecer.

Otro aspecto a tomar en cuenta sería lograr el reto que consiste en hacer que los 
ciudadanos adquieran nuevamente un sentido colectivo tal como ocurría en épocas anteriores. Esto es difícil porque en la actualidad el individualismo ha sido sobrevalorado. Entonces se requiere encontrar una o distintas maneras de hacer que las personas adquieran la convicción de que es importante y benéfico, para todos, poner en práctica actitudes y comportamientos que permitirían la solución parcial de conflictos sociales que a todos nos aquejan. En pocas palabras, el desafío radica en lograr que las personas se despojen un poco de su individualidad y se den cuenta de que muchos problemas sociales podrían ser solucionados si cada sujeto contribuye desde su actuar cotidiano, problemas tales como contaminación ambiental, calles sucias, instituciones deficientes, etc. Este aspecto es importante porque su carencia hace inviable la propuesta de una ética civil basada en virtudes públicas.

Finalmente, es de suma importancia que se reflexione más sobre cada virtud pública con el propósito de que sea planteada una descripción más precisa inherente a cada cualidad del ciudadano. Esto contribuiría en el sentido de que la propuesta sobre un catálogo de virtudes públicas pueda ser mejor difundida y analizada para que su difusión y aceptación pueda ser más prometedora y fructífera.

Retomando la pregunta inicial, digamos que es viable proponer y difundir una ética civil basada en virtudes públicas, puesto que todos anhelamos vivir en una mejor sociedad. Pero también es verdad que debe ser planteada de manera más sistemática y precisa. Ya hecho esto, entonces podríamos continuar con la búsqueda de los medios que harían posible su mejor difusión y aceptación social, lo cual en último término se vería reflejado en una mayor participación ciudadana que dará pie a mejoras sociales valiosas. Quizá nosotros nos ocupemos en realizar todo esto en un futuro trabajo cuando contemos con más elementos teóricos.

Al leer este capítulo no debe entenderse que estamos señalando la inexistencia de las virtudes públicas de solidaridad, responsabilidad y tolerancia, pues en demasiados casos podemos ser testigos de que existen muchos individuos con un sentido colectivo que les compromete a colaborar para la presencia de beneficios sociales. Una prueba de 
esto son las asociaciones civiles que han desempeñado un importante papel en lo que se refiere a la solución parcial de muchos problemas tales como el racismo, pobreza extrema, discriminación a grupos minoritarios, etc. Pero postular y difundir un catálogo de virtudes públicas tiene como fin último lograr que muchas personas colaboren, aunque sea en pequeñas cosas, en pro de beneficios sociales, pues existen muchas maneras de hacerlo tales como el ahorro de recursos naturales, reciclando, depositando la basura en los lugares apropiados, cuidando en la medida de lo posible la propia salud, respetando a quienes son diferentes a nosotros, entre muchas otras acciones. Estamos convencidos de que, si la mayoría de los ciudadanos colaboran llevando a cabo las prácticas mencionadas entre muchas otras, obviamente viviríamos en una mejor sociedad.

\section{Conclusiones}

Nuestra investigación tuvo como objetivo retomar postulados teóricos de la ética de la virtud en función de proponer una ética civil basada en un catálogo de virtudes públicas, tomando como referencia las reflexiones aportadas por Victoria Camps a este respecto.

En el último punto nuestro cometido fue postular un catálogo de virtudes públicas siguiendo las reflexiones de Victoria Camps a este respecto. Comenzamos explicando por qué es necesario en estos tiempos proponer unas virtudes públicas. Después hablamos un poco acerca de lo que consiste, he implica, una ética cívica o de mínimos según palabras de Adela cortina. A continuación, expusimos las tres virtudes públicas que, a juicio de Camps, son necesarias en la actual sociedad democrática y añadimos una breve descripción de cada una. Como resultado pudimos percibir que ella no planteó suficientemente una descripción de cada cualidad aludida. Entonces concluimos que, si en verdad pretendemos sugerir y difundir las virtudes públicas con resultados satisfactorios, requerimos desarrollar más la propuesta. Luego tendríamos que proceder con la aplicación de un proyecto educativo compatible con esta. Por último, lo fundamental sería lograr convencer a los ciudadanos haciéndoles ver la importancia y el 
beneficio de practicar las virtudes públicas expresándolas en pequeñas acciones cotidianas para conseguir mejoras sociales significativas.

La conclusión a la que llegamos, con el desarrollo de esta investigación, es que la ética de la virtud es una teoría interesante por sugerir un cambio de perspectiva en torno a la moral. En lugar de entenderla como normas que simplemente son impuestas, la consideremos como una serie de valores propuestos en un contexto con el fin de atender necesidades específicas que, de satisfacerse, nos ayudarían a mejorar como individuos, lo cual en última instancia se vería reflejado en mejoras sociales importantes. Entonces, consideramos que adoptar esta perspectiva implicaría una mayor motivación en las personas que les llevará a practicar las virtudes públicas. No obstante, nos dimos cuenta de que para lograr esto es necesario un desarrollo más sistemático de una ética civil basada en virtudes públicas que incorpore los aspectos anteriormente señalados entre los que se encuentra la forja de un buen carácter ciudadano mediante un proyecto educativo. Eficiente.

Por último, afirmamos que estamos convencidos de que recuperar las ideas fundamentales inherentes a la ética de la virtud es algo deseable, principalmente, porque pone más atención al carácter de las personas. Hacer esto permitiría la obtención de mejores resultados a la hora de plantear y difundir valores éticos necesarios en distintos contextos institucionales y sociales. La razón principal que podemos ofrecer de esta convicción es que en lugar de obligar a los individuos a que se comporten de tal o cual manera, más bien se les convenza por qué sería bueno y benéfico para sí mismos y los demás manifestar ciertas disposiciones y virtudes sugeridas en un contexto. Esto en último término contribuiría en evitar que las personas actúen simplemente por obligación, lo cual no posee valor moral, más bien sigan comportamientos y acciones gracias a buenas motivaciones, deseos y sentimientos, algo que evidentemente añade valor moral a lo que cualquier agente moral, persona, realiza. 